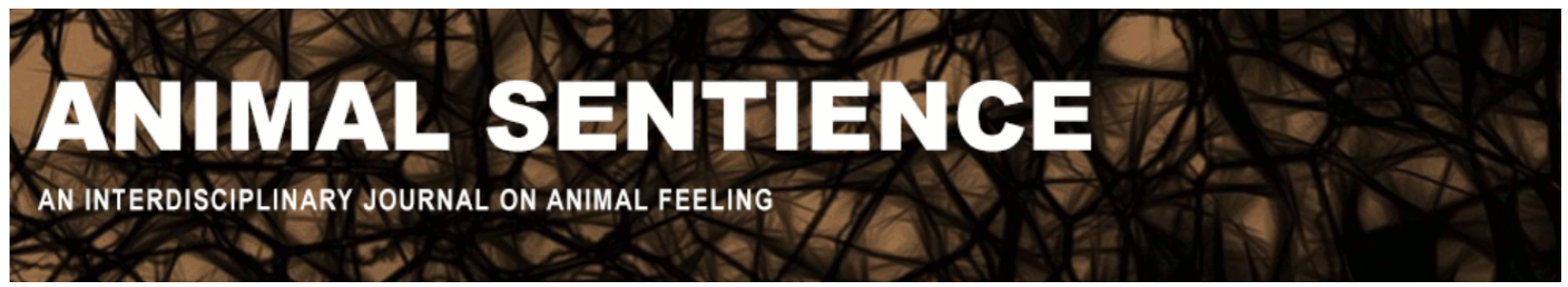

Racine, Timothy P. (2016) The grounds for animal subjectivity and intersubjectivity. Animal Sentience 1(3)

DOI: $10.51291 / 2377-7478.1108$

Date of submission: 2016-05-06

Date of acceptance: 2016-07-06 (c) 


\title{
The grounds for animal subjectivity and intersubjectivity
}

\author{
Commentary on Harnad on Other Minds
}

\author{
Timothy P. Racine \\ Department of Psychology \\ Simon Fraser University, Canada
}

\begin{abstract}
Harnad (2016) presents an engaging and persuasive argument that stakes out the aims and domain of the fledgling journal, Animal Sentience. As an inaugural editorial, it does this job masterfully, but it does so from a perspective that tends to treat mental states in an overly general manner and that makes hard distinctions between mental and behavioral phenomena. I argue that when it comes to animal minds, it might be more helpful to think of mental concepts in a more piecemeal way that also retains the intrinsic relation between mind and behavior.
\end{abstract}

Tim Racine is Associate Professor of History, Quantitative and Theoretical Psychology at Simon Fraser University. His scholarly interests concern the application of conceptual analysis to psychology and allied disciplines, the use of evolutionary theory in psychology, and the development of social cognition and related capacities in human and nonhuman primates.

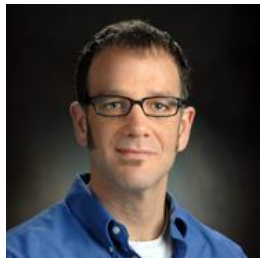
http://www.sfu.ca/psychology/about/faculty/racine.html

In the introduction to his insightful inaugural editorial, Harnad (2016) asks, "What does it mean to 'have a mind'?" His answer, in part a response to Descartes, is that it "feels like something to think ... or to be in any other mental state," and that therefore, "Mental states are felt states, and to have a mind means to have the capacity to feel. In a word: sentience" (Harnad, 2016, p. 3 , emphasis in original). Although defining mental states in this manner has the potential to unify human and nonhuman animal minds and the study thereof, it also poses at least three challenges.

First, as this position retains the Cartesian split between mind and behavior, it runs the risk of distorting the process of mental state attribution by assuming we can only be sure about our own minds but have to rely on inference for the minds of others; however, there is no certainty per se in the first-person case. Second, it collapses over a variety of differences in our mental vocabularies and geographies that are often better kept distinct; that is, whereas certain mental concepts essentially involve feelings, many do not, and furthermore, whereas we have a pretty good sense of what people mean when they claim they know what an object feels like, it is less clear what a felt mental state consists of (other than typically being accompanied by a verbal report or characteristic pattern of behavior as in other mental states). Third, when discussing mindreading, although it is helpful to know the content of a particular mental state, or whether one can even be sensibly attributed, it is also relevant to know whether the agents themselves 
understand their own mental life and that of others; although a capacity to feel is surely required for such understanding, it is not the same thing as it, and it is often useful to distinguish subjectivity from intersubjectivity.

Harnad's (2016) solution to these challenges seems to mostly lie in language; humans use languages to express our internal states to others and to understand the mental states of others; we can also, as language users, often infer the mental lives of others from their nonverbal behavior. Accordingly, then, the other-minds problem is minimal for humans in typical circumstances because we rely on our languages, and, particularly, in the case of nonverbal behavior, presumably also context. Therefore, for Harnad (2016), the problem of other minds mostly "arises only when speech is not possible and behavior is absent or minimal, such as in deep sleep or coma or under anaesthesia" (p. 3).

Kiley-Worthington's (2016) commentary takes issue with this characterization and points out that other animals are not comparable to preverbal or mentally challenged persons, nor are animals simply controlled by instincts (Wereha \& Racine, 2012). However, Kiley-Worthington's depiction of human language as context independent versus the context-dependent communication systems in many species tends to make human communication appear far less contextual than it actually might be, which can encourage us to easily overlook the necessary relation between mind and behavior no matter what species we might have in mind. I do agree with Harnad (2016) though that when it comes to the human folk psychological concepts that we typically import into our discussions of animal mentality, humans are the superior mind readers overall; it is important to bear in mind though that in many ways we have no choice, as human observers, but to apply human psychological concepts to nonhuman animals, thereby reinforcing this superiority.

One way to bring this point to life is to discuss Kiley-Worthington's (2016) use of Clever Hans as an example of mindreading. The point is well taken and it is indeed clever for a horse to behave in such a manner; it suggests quite a bit about sensitivity to subtle cues that humans often overlook. However, as clever as Hans might be, this would likely not pass muster as mindreading for a developmental psychologist even if performed by the cleverest of nonverbal humans. The reason is that this example would probably be seen as best explained as a learned association that does not require any inference about the minds of Clever Hans's audience or his trainer. Here though, one could argue that the other-minds problem truly takes center stage because if a behavior counts as mindreading in the right context, then why should it matter what causes the behavior to be exhibited? This runs the risk of conflating causal and definitional issues in mental state attribution (Racine, 2015). However, a horse tapping out a response to a math question is an unusual definition of mindreading and a restricted sense of the concept; we would probably want to see what else Clever Hans is able to do. Similarly, and less controversially perhaps, developmental and comparative psychologists continue to argue over whether pointing gestures, by ape or human, are learned, and the extent to which they index first order versus second order intentionality (Racine, 2012). How can debates like these be resolved? 
Harnad's (2016) position is helpful because it reminds us of the grounds for mental state attribution, which require the right sort of circumstances in the background for the verbal (or nonverbal) behavior to mean what it does. So, a human infant pointing to request an object from a caregiver in a typical Western family and a chimpanzee doing the same of a human caregiver from a cage would both be pointing in the same circumstances, and whatever mentality this evidences of the agents in question would be granted to both (Leavens \& Racine, 2009). Whether human infants do this because of mindreading skills and chimps do it because of social shaping might be interesting causally, if empirically tractable, but it would not tell us anything about the degree of mentality exhibited - unless one decides by fiat that anything that might be acquired instrumentally or through conditioning is less psychologically interesting (Tomasello, 2014). The problem though is that when the behavioral grounds for the attribution of some form of understanding are largely identical in human and nonhuman animals, as is the case in these sorts of request games, then there are no independent grounds for determining whether a given behavior requires some sort of special representational understanding that is potentially absent in nonhuman animals (Racine, 2012).

A way of getting around this issue might be to question the utility of the representational paradigm for nonhuman mentality, which is a move that Kiley-Worthington (2016) could be seen to imply. Johnson (2001), for example, suggests that a distributed model of cognition might be more fruitful for characterizing and investigating the mental lives of nonhuman animals. However, Harnad (2005) reminds us that, "the processes that generate thinking and know-how are 'distributed' within the heads of thinkers, but not across thinkers' heads" (p. 501). His conclusion is that "Hence, there is no such thing as distributed cognition." However, perhaps conceiving of "cognition as a family of interrelated but non-identical activities is helpful here because it avoids the need to make a dichotomous choice regarding whether or not cognition is distributed (or extended, situated, etc.)" (Susswein \& Racine, 2009, p. 186). And perhaps, whether or not cognition is literally distributed in the causal sense that Harnad (2005) seems to mean, it still might be a useful way to characterize some aspects of nonhuman mentality. For, although other animals seem not to understand more opaque concepts like belief (Tomasello, 2014), more basic concepts like attention or intention, which are more easily made manifest in nonverbal behavior, might be aptly described in a distributed manner.

Leavens, Racine, and Hopkins (2009) argue that joint attention is such a concept because it "necessarily requires a history of interaction between two or more subjects, some shared referent and some particular sociocultural and physical surround" (p. 12). They claim that "joint attention is paradigmatically a distributed cognitive act." Our claim is a definitional one; this is what counts as (joint) attention, and understood in this manner it can be useful to describe it as distributed cognition. It also makes it clear that whatever caused an agent to, for example, point in the right sort of pointing environment is independent of these definitional issues; to put this differently and with added strength, we can investigate the causes of joint attentional behavior because we know what counts as joint attention (Racine \& Müller, 2009). As Harnad (2016) also notes, we can also sometimes attribute mental state concepts by measuring brain activity and knowing that a particular brain state is correlated to a given mental state. In such a case, for example, a brain scan or EEG pattern can serve as a new definition for an existing concept; 
again, we know what counts as an understanding of beliefs, and when this part of the brain lights up we can count it as indexing belief understanding. All of this is good science.

For researchers interested not only in animal sentience but also animal intersubjectivity then, Harnad's (2016) other-minds challenge is particularly apt. Harnad's solution is also apt; other animals lack language, which is a primary way in which we express our mental states and understand them in others. An implication of this though is that sincere first-person reports of one's state of mind are incorrigible; unlike the third-person case, I cannot doubt my internal states, I can only express them. Of course, I can lie about my mental states, or can think or feel something that I do not express; in this sense Harnad is correct that there is always some problem of other minds. Although Harnad claims that animals, bereft of languages, face a more severe problem of other minds, he also opens the door to animal mentality by acknowledging that mental state attribution also involves nonverbal behavior, which, fleshed out a bit more, includes the context of attribution. In a similar way, Kiley-Worthington (2016) claims that animals, despite lacking language, do not really face such a problem because their communication is presumably embedded in mutually understood routines and practices.

I am in sympathy with Kiley-Worthington (2016), but also Harnad (2016) because humans are in some respects mind readers par excellence by virtue of the fact that human life can involve complicated forms of representation and intrinsically intersubjective linguistic symbols. I have also suggested that, at least for mental state attribution, communication is contextual, whether for human or nonhuman animals. I have argued further that depending on the mental state in question, human and nonhuman animals might well be at equal footing and that we have a tendency to elevate the mentality of humans over other animals by conflating the cause and definition of a mental state concept (Leavens \& Racine, 2009; Leavens et al., 2009; Racine, 2012). I have used the term "distributed cognition" to foreground its indexical nature, which also brings into focus the relation between the background circumstances of behavior and the attribution of mental state concepts. When mentality is framed in this manner, it is easier to see when human and nonhuman capacities converge - and where they diverge. However, there will always be some uncertainty about what is really in an agent's mind, whether a human or nonhuman animal; that is the nature of mental state concepts. This uncertainly though does not mean we should give similar patterns of behavior a starkly different meaning. For, it is behavioral similarity that is the most relevant factor for the attribution of the folk psychological concepts in this area of research; and, it might be this fact that underlies Harnad's (2016) observation that, "thanks to our acute mind-reading abilities, we grant the benefit of the doubt - to some degree - to mammals and birds, because they and their young resemble us (and especially resemble our young)" (p. 6).

The following quote from Wittgenstein (2009), which in part underscores the pragmatic context of decisions about what should and should not count as evidence for a particular mental state, suggests that there are no hard and fast rules here. It also implies that to the extent that we apply human mental state concepts to animals, it is often in a restricted and more rudimentary form. 
Look at a stone and imagine it having sensations. - One says to oneself: How could one so much get the idea of ascribing a sensation to a thing. One might as well ascribe it to a number! - And now look at a wriggling fly, and at once these difficulties vanish, and pain seems to get a foothold here, where before everything was, so to speak, too smooth. (§284, emphasis in original)

Why do we resist the application of sensation concepts to a stone? In some ways, it is simple as the fact that it is in our existing languages and the practices with which they are tied up, it makes no sense to do so in a literal sense, although perhaps it might in some restricted metaphorical use. It is not just language though; it is also the fact that humans tend to react differently to stones than we do to flies and other animals. Harnad's discussion of Descartes's view of animals provides insight into the ways that these uses and conceptions might change over historical time and cultural context. However, if it were determined, for example, that animals did not activate Descartes's mirror neuron system, such an empirical finding would have little bearing on the use of pain concepts (Racine, Wereha, \& Leavens, 2012). Things are different for flies, argues Wittgenstein, because they have the ability to behave in such a way as to exhibit what counts, at least roughly or pragmatically, as pain behavior. In most languages and the practices with which they are tied up, stones are not likely the sorts of objects that can have sensations; that is, to grasp the meaning of "sensation" is to know that one does not attribute such a concept to a stone.

Still, one might protest, how do we really know that a wriggling fly is in pain? This objection comes in large part, I suspect, as a consequence of the Cartesian view of mind; the belief that we know about our inner states by observing them through introspection, and, derivatively, by introspectively feeling them in the way that Harnad seems to mean. However, although we can believe something we later find to be false, we do not typically doubt (or not doubt) our own mental states because there are no grounds for doubt. By contrast, in the third-person case, we can and do get it wrong. For example, a human might well be in pain, but choose, stoically, not to express it linguistically or behaviorally. Similarly, a chimpanzee might well conceal an inner state from a conspecific in competitive circumstances (Tomasello, 2014). Therefore, from a point of view that sees mental state attribution as tied up with relevant patterns of behavior, the question of how we really know that a wriggling fly is in pain can equally be paraphrased, "Do we have grounds for doubting that a wriggling fly is in pain?" And one could equally ask, "Do we have reason to think that the wriggling fly is trying to pull one over on us when it exhibits what we would typically take to be pain behavior?" I take it that the obvious answer is no - and not because of facts about nervous systems, interesting as they might be, but rather facts about what counts as pain-behavior (and, for that matter, pretense).

In conclusion, as scientists or laypeople we have little choice but to use our existing languages and their motley crew of mental state concepts in our attempts to understand the minds of other animals. Although this makes language an important consideration when theorizing about animal minds, it should not be understood as a theoretical claim that language is a requirement for developing mental state concepts. This issue is more about the grounds for mental state attribution, which, as Harnad (2016) notes in the case of humans often involves language 
because what a person says of, for example, their intentions, desires and beliefs is an expression of those very states and therefore the best logical evidence for their possession. However, some mental states can be evidenced on behavioral grounds and these are states we can easily attribute to other animals. This is not anthropomorphism but rather concept use. Although this allows us to ascribe shared mentality when justified, for example, in the illustration of joint attention, as the Clever Hans case suggests, there are still logical limits to how far many human psychological concepts can be applied. The challenge for those interested in the investigation of animal subjectivity and intersubjectivity lies in part in applying our existing mental state concepts in ways that are sensitive to the needs of the scientist, but that do not unintentionally change their existing fields of meaning (Racine, 2015).

\section{References}

Harnad, S. (2005). Distributed processes, distributed cognizers, and collaborative cognition. Pragmatics \& Cognition, 13, 501-514.

Harnad, S. (2016). Animal sentience: The other-minds problem. Animal Sentience 2016.001.

Johnson, C. M. (2001). Distributed primate cognition: a review. Animal Cognition, 4, 167-183.

Kiley-Worthington, M. (2016). Nonhuman mind-reading ability. Animal Sentience 2016.070.

Leavens, D. A., \& Racine, T. P. (2009). Joint attention in apes and humans: Are humans unique? Journal of Consciousness Studies, 16, 240-267.

Leavens, D. A., Racine, T. P., \& Hopkins, W. D. (2009). The ontogeny and phylogeny of nonverbal deixis. In R. Botha \& C. Knight (Eds.), The cradle of language. Volume 1: Multidisciplinary perspectives (pp. 142-165). Oxford, UK: Oxford University Press.

Racine, T. P. (2012). Getting beyond rich and lean views of joint attention. In A. Seemann (Ed.), Joint attention: New developments in psychology, philosophy of mind, and social neuroscience (pp. 21-42). Cambridge, MA: MIT Press.

Racine, T. P. (2015). Conceptual analysis. In J. Martin, J. Sugarman, \& K. L. Slaney (Eds.), The Wiley handbook of theoretical and philosophical psychology: Methods, approaches and new directions for social science (pp. 39-52). London: Wiley.

Racine, T. P., \& Müller, U. (2009). The contemporary relevance of Wittgenstein: Reflections and directions. New Ideas in Psychology, 27, 107-117.

Racine, T. P., Wereha, T. J., \& Leavens, D. A. (2012). Primates, motion, and emotion: To what extent nonhuman primates are intersubjective and why. In A. Foolen, U. Lüdtke, T. P. Racine, 
\& J. Zlatev (Eds.), Moving ourselves, moving others: Motion and emotion in intersubjectivity, consciousness and language (pp. 221-242). Amsterdam: Benjamins.

Susswein, N., \& Racine, T. P. (2009). Wittgenstein and not-just-in-the-head cognition. New Ideas in Psychology, 27, 184-196.

Tomasello, M. (2014). A natural history of human thinking. Cambridge, MA: Harvard University Press.

Wereha, T. J., \& Racine, T. P. (2012). Evolution, development, and human social cognition. Review of Philosophy and Psychology, 3, 559-579.

Wittgenstein, L. (2009). Philosophical investigations (P. M. S. Hacker \& J. Schulte, Eds.). Oxford, UK: Wiley-Blackwell. 